\title{
Is Periventricular Leukomalacia an Axonopathy as Well as an Oligopathy?
}

\author{
OLAF DAMMANN, HENRIK HAGBERG, AND ALAN LEVITON \\ Neuroepidemiology Unit, Department of Neurology, Children's Hospital, Boston, Massachusetts 02115, \\ U.S.A. [O.D., A.L.]; Perinatal Center, Department of Obstetrics and Gynecology, Institute for the Health \\ of Women and Children, Göteborg University, Göteborg, Sweden [H.H.]
}

\begin{abstract}
ABS
Periventricular leukomalacia is a white matter disorder, the
neonatal cranial ultrasound images of which predict long-term
developmental limitations among preterm infants. The vulnera-
bility of oligodendrocytes has led to the hypothesis that oligo-
dendrocytes suffer the primary damage, with axonal damage
occurring as a consequence. In this article, we discuss the
differential role of oligodendrocytes and axons in this disorder's
etiology, offering analogies from the multiple sclerosis and hy-
drocephalus literature. We conclude that it is too early to view
periventricular leukomalacia exclusively as a consequence of
\end{abstract}
The ultrasonographic characteristics of neonatal white matter damage (often called PVL) predict motor and mental disorders among preterm infants (1). Early in the pathogenetic process, oligodendrocyte development is impaired and oligodendrocyte survival diminished (2). Axons are also damaged in PVL (2), but when this process is initiated is not yet known. According to current beliefs, PVL is a disease that begins as an epidemic among one type of tree (i.e. oligodendrocytes), and eventually involves the neighboring forest (i.e. axons). The evidence for this concept is analyzed in this review and alternative hypothetical pathways are presented.

Recent studies of people with multiple sclerosis indicate that axonal injury is, in part, independent of demyelinating activity, and that the pathogenesis of axon damage may be different from that of demyelination (3). This suggests that strategies to reduce deficits in people with early multiple sclerosis need to be based on preventing both demyelination and axonal loss. The same can be said for reducing the deficits that are attributable to neonatal white matter damage. It is also important to

Received April 12, 2000; accepted August 10, 2000.

Correspondence: Henrik Hagberg, M.D., Ph.D., Perinatal Center, Department of Obstetrics and Gynecology, Institute for the Health of Women and Children, Göteborg University, S-41685 Göteborg, Sweden; e-mail: henrik.hagberg@obgyn.gu.se

Supported by the United Cerebral Palsy Research and Educational Foundation (EH003-98) and the Swedish Medical Research Council (33x-09455-10B). oligodendrocyte damage and/or maldevelopment. (Pediatr Res 49: 453-457, 2001)

COX, cyclooxygenase
ELBW, extremely low birth weight
MRI, magnetic resonance image
NAA, $N$-acetyl aspartate
PVL, periventricular leukomalacia
TNF, tumor necrosis factor

try to understand if it is a primary oligopathy or axonopathy in the context of finding relevant in vitro or in vivo model systems for PVL. For example, isolated oligodendrocyte precursors may be the model of choice in a situation of a primary oligopathy (4), whereas in the case of a primary axonopathy, the isolated nonmyelinated optic nerve preparation or cultures with mixed cell types may be complementary (5).

Axonal disruption is a classic feature of PVL. Banker and Larroche's (6) original description of the morphologic characteristics of PVL included "retraction balls and clubs" (i.e. the varicose swelling of axon-cylinders). Recent reports have called for renewed attention to the axons in PVL. Amyloid precursor protein, a marker of axonal damage (7), has been found in the brains of infants who die with PVL, even in areas remote from focal necrosis (8-10). In addition, a form of optic nerve hypoplasia seen in children who had PVL has been attributed to axonal damage in the optic radiations (11). Axonal transections have been visualized in necrotic white matter lesions using silver staining or immunocytochemistry with antineurofilament antibodies (12). Marin-Padilla (12) states that "a generalized reduction of axonic fibers is a direct consequence of any acquired white matter lesion (hydrocephalus ex-vacuo)."

When evaluated at term, premature infants who had earlier ultrasonographic and MRI evidence of periventricular white 
matter injury had a marked reduction in cerebral cortical gray matter (an indicator of neuron/axon damage) not seen in premature infants without periventricular white matter injury (13).

Some children with motor symptoms usually attributed to sonographically evident PVL do not develop (gray matterrelated) cognitive limitations (14). Because white matter contains both oligodendroglial and axonal components, whereas gray matter is mainly composed of cell bodies of neurons, the inference is that neurons are not usually diffusely affected in children with PVL.

Understanding the role of axonal damage in PVL holds the promise of providing insights that might help prevent disability in the most vulnerable very preterm newborn. Some infants born at term who develop cerebral palsy also have the cranial MRI signature of PVL (15). To the extent that the motor, cognition, perception, and behavior disorders that occur in those born at term reflect disturbances near the end of the second trimester, a better understanding of axonal damage in PVL might also help reduce the risk of disability in infants born near term.

One set of hypotheses about PVL onset postulates that ischemia is the basic mechanism leading to PVL. Another set postulates a contribution from circulating or locally produced toxins that promote cell injury. Both of these hypotheses are examples of the common antecedent pathway (identified as pathway 1 in Fig. 1). In the other pathways, axonal damage is secondary to oligodendrocyte injury (pathway 2), and oligodendrocyte damage is a consequence of axonal injury (pathway 3).

\section{PVL AS A DIFFUSE WHITE MATTER DISORDER}

Perinatal telencephalic leucoencephalopathy (16) and its variants $(17,18)$ were originally considered early expressions of PVL. One variant was characterized by diffuse astrocytosis. The concept that diffuse white matter damage precedes focal necroses in cerebral white matter has received support from a

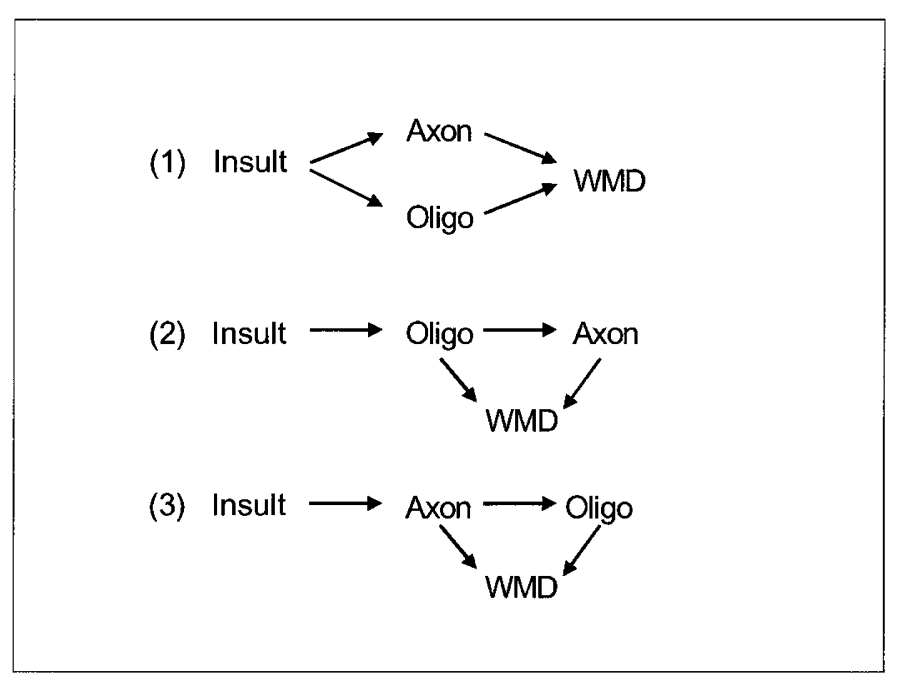

Figure 1. Three possible pathways by which an insult might lead to white matter damage (WMD) via axonal/oligodendrocyte (oligo) involvement. recent report using diffusion-weighted MRI and cranial ultrasound scans (19).

Several other observations support the hypotheses that "diffuse white matter damage" is part of PVL, and that oligodendrocytes can be severely affected. However, none of the following observations gives us a direct clue as to what cell type is primarily affected, or which contributes most to the apparent damage.

First, the very low gestational age newborn with one or only a few small cerebral white matter echolucencies during the first months is likely to have an MRI months later characterized by a generalized (i.e. nonfocal) paucity of white matter (20). These characteristics are reduced white matter bulk, unquestioned ventriculomegaly, and thinning of the corpus callosum. We still do not know whether the myelination delay is the result of a primary loss of oligodendrocytes, if the loss of oligodendrocytes is secondary to a loss of axons, or myelination delay represents an impairment of oligodendrocyte function. Second, the very low gestational age newborn with one, or only a few, small cerebral white matter echolucencies during the first months is likely to have motor disabilities that do not correlate with the location and magnitude of sonographically evident white matter damage (1). Third, half the very low gestational age newborns who develop cerebral palsy do not have cerebral white matter echolucencies during their first months $(21,22)$, even though some of them develop the characteristic MRI picture of white matter paucity. Fourth, DNA fragmentation is seen in glial cells in laboratory models of fetal/neonatal white matter damage $(23,24)$, which presumably represent selective "diffuse" apoptotic death of oligodendroglia. The functional significance of such a loss of oligodendroglia is uncertain, as these cells may, or may not, be easily replaced by preoligodendroglia.

\section{PVL AS OLIGOPATHY}

We, and other students of white matter damage, often refer to oligodendrocytes as "oligos." Thus, it seems reasonable to use the term oligopathy to emphasize that the characteristic of PVL is primary damage to oligodendrocytes. Yes, it is a play on the word oligopoly, but we use the term oligopathy so that it can be contrasted to the already accepted term axonopathy (25). Oligopathy may not be ideal, but we view it as preferable to oligodendrocytopathy.

Why should a disorder of oligodendrocytes be accompanied by axonal injury at all? In essence, if PVL is an oligopathy, why does it also have characteristics of an axonopathy? This question is especially important for a disorder that seems to begin during midpregnancy, when almost all axons are presumed to be unmyelinated.

\section{AXONOPATHY: PVL-MULTIPLE SCLEROSIS ANALOGY}

Some of the answers come from the multiple sclerosis literature, where it now seems that permanent deficits in patients with multiple sclerosis are more closely related to evidence of axonal damage than to plaque location (26-28). Postmortem studies also show that transected axons are most 
evident in lesions with the most inflammation (29), that axon density is reduced in demyelinated and remyelinated lesions (30), and that amyloid precursor protein is also expressed in axons within acute multiple sclerosis lesions (31).

Let us return to Figure 1, viewing white matter damage broadly. This allows us to apply it to multiple sclerosis as well as PVL, cerebral palsy, and chronic inflammatory demyelinating neuropathy.

Pathway 1. In this pathway, what damages oligodendrocytes also damages axons. One group of hypotheses postulates that soluble inflammatory mediators produced by activated leukocytes as well as by astrocytes, microglia, and endothelial cells (e.g. proteolytic enzymes, cytokines, and free radicals or other oxidative products), damage both oligodendrocytes and axons (28). Several findings support this view. First, measures of axonal injury in multiple sclerosis are most evident in areas of inflammation and demyelination (29-31). Second, proinflammatory cytokines are found at higher levels in the brains of infants who die with periventricular leukomalacia than in the brains of infants without evidence of white matter damage (10, 32, 33). Deguchi et al. (10) stated that, "In ELBW (extremely low birth weight) infants, widespread axonal damage and glial activation with cytokine production occur in the progression in characteristic PVL lesions." Third, preterm infants who developed cerebral palsy had higher levels of proinflammatory cytokines in their amniotic fluid than their peers who did not develop cerebral palsy (34). Among term infants, those who went on to develop cerebral palsy had higher circulating levels of proinflammatory cytokines just days after birth than infants who did not develop cerebral palsy $(35,36)$. Fourth, in nerve biopsies from adults with chronic inflammatory demyelinating neuropathy, immunocytochemical expression of TNF- $\alpha$ was most prominent in phagocytosing macrophages in zones of acute axonal injury (37). This is additional support for the axon-damaging capability of proinflammatory cytokines.

Because glutamate and other agonists of excitatory amino acid receptors are released in large quantities by activated immune cells $(38-40)$ (perhaps the same that produce TNF- $\alpha$ and other cytokines), excitotoxicity might contribute to the occurrence of axon damage associated with activated immune cells. Experimental autoimmune encephalomyelitis is a laboratory model of multiple sclerosis in which damage is attributed to the effects of activated immune cells. Blockade of the $\alpha$-amino-3-hydroxy-5-methyl-4-isoxazole propionic acid (AMPA) subtype of excitatory amino acid receptors in mice sensitized for experimental autoimmune encephalomyelitis reduced the amount of a chemical indicator of axonal damage (41) and ameliorated the neurologic sequelae of experimental autoimmune encephalomyelitis (42). Correspondingly, axonal lesions are produced by the direct injection of the $N$-methylD-aspartate (NMDA) receptor agonist ibotenate into the immature rodent brain (43), an action that seemed to depend on proinflammatory cytokines (44). The mechanism of such "axonal toxicity" is, however, unclear and may involve activation of excitatory amino acid receptors on neuronal postsynaptic sites in the gray matter rather than being a direct effect on axons or glia in the white matter.
Another set of hypotheses postulates that ischemiareperfusion is the basic disturbance leading to PVL. In fetal sheep, amyloid precursor protein immunostaining is evident as early as $1 \mathrm{~d}$ after cord occlusion (45). The complexity of the interrelationships among the contributors to white matter damage is underscored by the observation that ischemic cell death of immature oligodendrocytes occurs via mechanisms involving non- $N$-methyl-D-aspartate (NMDA) glutamate receptors (46).

However, a clear-cut dichotomy between ischemiareperfusion and products of inflammation as initiators of damage is unlikely, because COX-2, a component of inflammatory processes, can also be detected as early as $1 \mathrm{~d}$ after cord occlusion (45). Support for the involvement of proinflammatory cytokines in hypoxic-ischemic models of brain damage comes from our group $(47,48)$ and others $(49,50)$.

Pathway 2. In this pathway, axons are damaged because of the loss of axonotrophic factors that follow oligodendrocyte damage. Two sets of hypotheses deserve comment. One set postulates that the trophic factor is in myelin (51). Indeed, axon caliber seems to be reduced whenever the relationship between myelinating glia and axon is missing or disrupted (52). At least two signaling pathways seem to be involved. A local signal modulates local "packing density" of neurofilaments in the axon (53). The other, a retrograde signal, influences maturation of the axon cytoskeleton (54).

The other set of hypotheses postulates that, independent of myelination, oligodendrocytes regulate axon caliber during development (55). Two findings suggest that myelin-associated glycoprotein is one of the oligodendrocyte-derived axonotrophins. Mouse axons that are normally myelinated but deficient in myelin-associated glycoprotein undergo atrophy (56). Also, myelin-associated glycoprotein, a member of the immunoglobulin gene superfamily, is localized exclusively in the adaxonal membrane of myelin (57).

On the other hand, axonal growth and regeneration are hampered by the myelin-associated neurite inhibitor IN-1 that is produced by oligodendrocytes. Indeed, killing of oligodendrocytes by $\mathrm{X}$-irradiation in newborn rats results in axonal hypertrophy and enhances axonal regeneration (58). This exemplifies the complexity of the relationship between oligodendrocyte and axon.

Lysolecithin-induced demyelination in primates has been used to study bystander demyelination in multiple sclerosis (59). Eradication of oligodendrocytes by lysolecithin induces demyelination, which is followed by at least partial remyelination of intact axons by either regenerating oligodendrocytes or transformed glia. Among other things, these findings suggest that the loss of oligodendrocytes need not result in axonal injury $(60,61)$.

Zones of decreased amounts of NAA in proton magnetic resonance spectroscopic images of the brain are viewed as an in vivo marker of axonal damage (62). The NAA:Cr ratio is lower in the region of plaques than in the normal-appearing white matter of multiple sclerosis patients, which in turn is lower than in the normal-appearing white matter of people who do not have multiple sclerosis (27). This has led to the view 
that axonal damage is sometimes remote from the plaques that characterize multiple sclerosis.

Plaques (seen on MRI) are to multiple sclerosis what echolucencies (seen on ultrasound scans) are to PVL. Both plaques and echolucencies are the tip of the iceberg of white matter damage. Terry Inder and her colleagues (19) have recently reported that diffusion weighted images allow recognition of diffuse white matter damage even before focal cysts become apparent on conventional MRI. Consider the possibility that when diffusion-weighted imaging, which detects early white matter injury, and NAA ascertainment, which detects early axonal injury, are combined to study the brains of children with PVL, interesting information on the axonopathy-oligopathy relationship is likely to be obtained.

Pathway 3. In this pathway, damage to axons is first, followed by damage to (or reduction in number of) oligodendrocytes. For example, transection of adult rat optic nerves rapidly results in a $90 \%$ decrease in number of oligodendrocytes (63). This reduction in oligodendrocyte number seemed to be associated with the reduced availability of axondependent survival factors (here, ciliary neurotrophic factor and IGF-I). After addition of neurons, survival of purified cultured oligodendrocytes increased more than 10-fold. However, pathway 3 seems unlikely because oligodendrocytes are considerably more vulnerable during maturation than are other glial cells in cultures deprived of cystine, depleted of glutathione or exposed to combined hypoxia and hypoglycemia $(4,46$, 64) or compared with the resistance of nonmyelinated axons exposed to anoxia (5).

\section{AXONOPATHY: PVL-HYDROCEPHALUS ANALOGY}

Although we have so far relied on multiple sclerosis as the adult analogy to neonatal white matter damage, the white matter damage that follows the onset of hydrocephalus in newborns might be a closer analogy. Axonal degeneration in the white matter was seen in needle biopsies of the cerebral mantle of children (ages $14 \mathrm{~d}$ to $3 \mathrm{y}$ ) with acute hydrocephalus, although progressive gliosis was seen in more chronic hydrocephalus, together with signs of cerebral atrophy (65).

In one of the more popular animal models of hydrocephalus, kaolin is injected into the cisterna magna $(66,67)$. This is followed by reactive gliosis, white matter atrophy, and, in some animals, gross cavitation of the white matter. The white matter changes are very similar to those seen in periventricular leukomalacia (66). Can all these characteristics of white matter damage be attributed to hydrocephalus? Is it possible that kaolin has oligotoxic properties?

In one report, axonal damage in the periventricular white matter occurs within days of kaolin-induced hydrocephalus (66). In another, myelin-related enzyme activity in the medulla and spinal cord was reduced early, "even before irreversible (axonal) damage occurred in the corticospinal tracts" (67). In a third report, "some axons in the corpus callosum were injured as early as $1 \mathrm{wk}$, but axonal damage was not prevalent until 4 wk when ventriculomegaly became severe" (68). Thus, it is too soon to say whether early axonal damage in acute hydrocephalus precedes or follows early oligodendrocyte damage.
Unfortunately, in addition to diminishing cerebrospinal fluid reabsorption, kaolin interferes with endothelial cell function (69). Thus, kaolin might disrupt the blood-brain barrier, allowing the entry of clay particles into the brain where they might do more damage. Mature oligodendroglia are not lysed by kaolin (69). We could not find any report of the effect of kaolin on immature oligodendroglia. Until the effects of kaolin on oligodendrocytes and axons are clarified, we consider it premature to offer kaolin-induced hydrocephalus as a model for studying oligopathy and axonopathy.

\section{THE FUTURE}

Follow-up assessments of children who were evaluated with proton magnetic resonance spectroscopy - the best available in vivo marker of axonal damage $(26,27,62)$, diffusion-weighted MRI, the best available identifier of early white matter damage (19), and other MRI techniques that reliably assess white and gray matter volume (13)—will improve our understanding of the temporal and geographical relationships between early white matter lesions and axon damage in the brains of children at risk of both (e.g. who have PVL or acute hydrocephalus). Such studies will also increase our knowledge of the relative contributions of axonal and oligodendrocyte damage to functional limitations.

We hope that those who study the effects of kaolin on developing brain will evaluate the effects on oligodendrocytes and axons in vitro, each separately, and then in mixed cultures to assess to what extent results from kaolin-induced models of hydrocephalus extrapolate to children who had neonatal hydrocephalic or PVL. Furthermore, additional in vitro and in vivo studies in animals are needed to explore the interaction between the different cellular constituents of the white matter in the response to various insults $(2,5,24,44,46)$.

\section{CONCLUSION}

In conclusion, we have offered support for the view that white matter damage involves both axons and oligodendrocytes. Currently, there is no conclusive proof that white matter damage (diffuse or focal) is caused primarily by a selective loss of oligodendroglia. It is likely, however, that the deficit of oligodendroglia, loss of axonal fibers, microgliosis, and astrogliosis all contribute to PVL pathogenesis.

\section{REFERENCES}

1. Holling EE, Leviton A 1999 Characteristics of cranial ultrasound white matter echolucencies that predict disability: a review. Dev Med Child Neurol 41:136-139

2. Kinney HC, Back SA 1998 Human oligodendroglial development: relationship to periventricular leukomalacia. Semin Pediatr Neurol 5:180-189

3. Bitsch A, Schuchardt J, Bunkowski S, Kuhlmann T, Bruck W 2000 Acute axonal injury in multiple sclerosis: correlation with demyelination and inflammation. Brain 123:1174-1183

4. Back SA, Volpe JJ 1997 Cellular and molecular pathogenesis of periventricular white matter injury. Mental Retard Dev Disabil Res Rev 3:96-107

5. Fern R, Davis P, Waxman SG, Ransom BR 1998 Axon conduction and survival in CNS white matter during energy deprivation: a developmental study. J Neurophysiol 79:95-105

6. Banker BQ, Larroche JC 1962 Periventricular leukomalacia of infancy. Arch Neurol $7: 386-410$

7. Yam PS, Takasago T, Dewar D, Graham DI, McCulloch J 1997 Amyloid precursor protein accumulates in white matter at the margin of a focal ischaemic lesion. Brain Res 760:150-157 
8. Arai Y, Deguchi K, Mizuguchi M, Takashima S 1995 Expression of beta-amyloid precursor protein in axons of periventricular leukomalacia brains. Pediatr Neurol 13:161-163

9. Meng SZ, Arai Y, Deguchi K, Takashima S 1997 Early detection of axonal and neuronal lesions in prenatal-onset periventricular leukomalacia. Brain Dev 19:480484

10. Deguchi K, Oguchi K, Takashima S 1997 Characteristic neuropathology of leukomalacia in extremely low birth weight infants. Pediatr Neurol 16:296-300

11. Jacobson L, Hellstrom A, Flodmark O 1997 Large cups in normal-sized optic discs: a variant of optic nerve hypoplasia in children with periventricular leukomalacia. Arch Ophthalmol 115:1263-1269

12. Marin-Padilla M 1997 Developmental neuropathology and impact of perinatal brain damage. II: white matter lesions of the neocortex. J Neuropathol Exp Neurol 56:219-235

13. Inder TE, Hüppi PS, Warfield S, Kikinis R, Zientara GP, Barnes PD, Jolesz F, Volpe JJ 1999 Periventricular white matter injury in the premature infant is followed by reduced cerebral cortical gray matter volume at term. Ann Neurol 46:755-60

14. Dammann O, Walther H, Allers B, Schröder M, Drescher J, Lutz D, Veelken N, Schulte FJ 1996 Development of a regional cohort of very-low-birthweight children at six years: cognitive abilities are associated with neurological disability and social background. Dev Med Child Neurol 38:97-106

15. Truwit CL, Barkovich AJ, Koch TK, Ferriero DM 1992 Cerebral palsy: MR findings in 40 patients. AJNR Am J Neuroradiol 13:67-78

16. Gilles FH, Murphy SF 1969 Perinatal telencephalic leucoencephalopathy. J Neuro Neurosurg Psychiatry 32:404-413

17. Leviton A, Gilles FH 1973 Are hypertrophic astrocytes a sufficient criterion of perinatal telencephalic leucoencephalopathy? J Neurol Neurosurg Psychiatry 36:383388

18. Leviton A, Gilles FH 1974 Morphologic abnormalities in human infant cerebral white matter related to gestational and postnatal age. Pediatr Res 8:718-720

19. Inder T, Hüppi PS, Zientara GP, Maier SE, Jolesz FA, di Salvo D, Robertson R, Barnes PD, Volpe JJ 1999 Early detection of periventricular leukomalacia by diffusion-weighted magnetic resonance imaging techniques. J Pediatr 134:631-634

20. Skranes JS, Nilsen G, Smevik O, Vik T, Brubakk AM 1998 Cerebral MRI of very low birth weight children at 6 years of age compared with the findings at 1 year. Pediatr Radiol 28:471-475

21. Pinto-Martin JA, Riolo S, Cnaan A, Holzman C, Susser MW, Paneth N 1995 Crania ultrasound prediction of disabling and nondisabling cerebral palsy at age two in a low birth weight population. Pediatrics 95:249-254

22. O'Shea TM, Klinepeter KL, Dillard RG 1998 Prenatal events and the risk of cerebral palsy in very low birth weight infants. Am J Epidemiol 147:362-369

23. Yoon BH, Kim CJ, Romero R, Jun JK, Park KH, Choi ST, Chi JG 1997 Experimentally induced intrauterine infection causes fetal brain white matter lesions in rabbits. Am J Obstet Gynecol 177:797-802

24. Debillon T, Gras-Leguen C, Verielle V, Winer N, Caillon J, Roze JC, Gressens P 2000 Intrauterine infection induces programmed cell death in rabbit periventricula white matter. Pediatr Res 47:736-742

25. Scherer SS, Fischbeck KH 1999 Is CMTX an axonopathy? Neurology 52:432-433

26. Matthews PM, De Stefano N, Narayanan S, Francis GS, Wolinsky JS, Antel JP, Arnold DL 1998 Putting magnetic resonance spectroscopy studies in context: axonal damage and disability in multiple sclerosis. Semin Neurol 18:327-336

27. Fu L, Matthews PM, De Stefano N, Worsley KJ, Narayanan S, Francis GS, Antel JP, Wolfson C, Arnold DL 1998 Imaging axonal damage of normal-appearing white matter in multiple sclerosis. Brain 121:103-113

28. Lycke JN, Karlsson JE, Andersen O, Rosengren LE 1998 Neurofilament protein in cerebrospinal fluid: a potential marker of activity in multiple sclerosis. J Neurol Neurosurg Psychiatry 64:402-404

29. Trapp BD, Peterson J, Ransohoff RM, Rudick R, Mork S, Bo L 1998 Axona transection in the lesions of multiple sclerosis. N Engl J Med 338:278-285

30. Mews I, Bergmann M, Bunkowski S, Gullotta F, Bruck W 1998 Oligodendrocyte and axon pathology in clinically silent multiple sclerosis lesions. Mult Scler 4:55-62

31. Ferguson B, Matyszak MK, Esiri MM, Perry VH 1997 Axonal damage in acute multiple sclerosis lesions. Brain 120:393-399

32. Deguchi K, Mizuguchi M, Takashima S 1996 Immunohistochemical expression of tumor necrosis factor alpha in neonatal leukomalacia. Pediatr Neurol 14:13-16

33. Yoon BH, Romero R, Kim CJ, Koo JN, Choe G, Syn HC, Chi JG 1997 High expression of tumor necrosis factor-alpha and interleukin-6 in periventricular leukomalacia. Am J Obstet Gynecol 177:406-411

34. Yoon BH, Jun JK, Romero R, Park KH, Gomez R, Choi JH, Kim IO 1997 Amniotic fluid inflammatory cytokines (interleukin-6, interleukin- 1beta, and tumor necrosis factor-alpha), neonatal brain white matter lesions, and cerebral palsy. Am J Obstet Gynecol 177:19-26

35. Nelson KB, Dambrosia JM, Grether JK, Phillips TM 1998 Neonatal cytokines and coagulation factors in children with cerebral palsy. Ann Neurol 44:665-675

36. Grether JK, Nelson KB, Dambrosia JM, Phillips TM 1999 Interferons and cerebral palsy. J Pediatr 134:324-332

37. Oka N, Akiguchi I, Kawasaki T, Mizutani K, Satoi H, Kimura J 1998 Tumor necrosis factor-alpha in peripheral nerve lesions. Acta Neuropathol (Berl) 95:57-62

38. Giulian D, Li J, Leara B, Keenen C 1994 Phagocytic microglia release cytokines and cytotoxins that regulate the survival of astrocytes and neurons in culture. Neurochem Int 25:227-233

39. Koennecke LA, Zito MA, Proescholdt MG, van Rooijen N, Heyes MP 1999 Depletion of systemic macrophages by liposome-encapsulated clodronate attenuates in- creases in brain quinolinic acid during CNS-localized and systemic immune activation. J Neurochem 73:770-779

40. Piani D, Frei K, Do K, Cuenod M, Fontana A 1991 Murine brain macrophages induce NMDA receptor mediated neurotoxicity in vitro by secreting glutamate. Neurosci Lett 133:159-162

41. Pitt D, Werner P, Raine CS 2000 Glutamate excitotoxicity in a model of multiple sclerosis. Nat Med 6:67-70

42. Smith T, Groom A, Zhu B, Turski L 2000 Autoimmune encephalomyelitis ameliorated by AMPA antagonists. Nat Med 6:62-66

43. Marret S, Mukendi R, Gadisseux JF, Gressens P, Evrard P 1995 Effect of ibotenate on brain development: an excitotoxic mouse model of microgyria and posthypoxiclike lesions. J Neuropathol Exp Neurol 54:358-370

44. Dommergues MA, Patkai J, Renauld JC, Evrard P, Gressens P 2000 Proinflammatory cytokines and interleukin-9 exacerbate excitotoxic lesions of the newborn murine neopallium. Ann Neurol 47:54-63

45. Ohyu J, Marumo G, Ozawa H, Takashima S, Nakajima K, Kohsaka S, Hamai Y, Machida Y, Kobayashi K, Ryo E, Baba K, Kozuma S, Okai T, Taketani Y 1999 Early axonal and glial pathology in fetal sheep brains with leukomalacia induced by repeated umbilical cord occlusion. Brain Dev 21:248-252

46. Fern R, Moller T 2000 Rapid ischemic cell death in immature oligodendrocytes: a fatal glutamate release feedback loop. J Neurosci 20:34-42

47. Hagberg H, Gilland E, Bona E, Hanson L, Hahn-Zoric M, Blennow M, Holst M, McRae A, Söder O 1996 Enhanced expression of interleukin (IL)-1 and IL-6 messenger RNA and bioactive protein after hypoxia-ischemia in neonatal rats. Pediatr Res 40:603-609

48. Bona E, Andersson AL, Blomgren K, Gilland E, Puka-Sundvall M, Gustafson K, Hagberg H 1999 Chemokine and inflammatory cell response to hypoxia-ischemia in immature rats. Pediatr Res 45:500-509

49. Palmer C 1995 Hypoxic-ischemic encephalopathy. Therapeutic approaches against microvascular injury, and role of neutrophils, PAF, and free radicals. Clin Perinatol $22: 481-517$

50. Silverstein FS, Barks JDE, Hagan P, Liu XH, Ivacko J, Szaflarski J 1997 Cytokines and perinatal brain injury. Neurochem Int 30:375-383

51. Windebank AJ, Wood P, Bunge RP, Dyck PJ 1985 Myelination determines the caliber of dorsal root ganglion neurons in culture. J Neurosci 5:1563-1569

52. Will A, Brady ST 2000 Unwrapping new layers of complexity in axon/glial relationships. Glia 29:112-117

53. de Waegh SM, Lee VMY, Brady ST 1992 Local modulation of neurofilament phosphorylation, axonal caliber, and slow axonal transport by myelinating Schwann cells. Cell 68:451-463

54. Brady ST, Witt A, Kirkpatrick LL, Waegh SMD, Readhead C, Tu PH, Lee VMY 1999 Formation of compact myelin is required for maturation of the axonal cytoskeleton. J Neurosci 19:7278-7288

55. Sanchez I, Hassinger L, Paskevich PA, Shine HD, Nixon RA 1996 Oligodendroglia regulate the regional expansion of axon caliber and local accumulation of neurofilaments during development independently of myelin formation. J Neurosci 16:50955105

56. Fruttiger M, Montag D, Schachner M, Martini R 1995 Crucial role for the myelinassociated glycoprotein in the maintenance of axon-myelin integrity. Eur J Neurosci 7:511-515

57. Trapp BD, Andrews SB, Cootauco C, Quarles R 1989 The myelin-associated glycoprotein is enriched in multivesicular bodies and periaxonal membranes of actively myelinating oligodendrocytes. J Cell Biol 109:2417-2426

58. Schwab ME, Bartholdi D 1996 Degeneration and regeneration of axons in the lesioned spinal cord. Physiol Rev 76:319-370

59. Dousset V, Brochet B, Vital A, Gross C, Benazzouz A, Boullerne A, Bidabe AM, Gin AM, Caille JM 1995 Lysolecithin-induced demyelination in primates: preliminary in vivo study with MR and magnetization transfer. Am J Neuroradiol 16:225-231

60. Blakemore WF, Patterson RC 1978 Suppression of remyelination in the CNS by X-irradiation. Acta Neuropathol (Berl) 42:105-113

61. Honmou O, Felts PA, Waxman SG, Kocsis JD 1996 Restoration of normal conduction properties in demyelinated spinal cord axons in the adult rat by transplantation of exogenous Schwann cells. J Neurosci 16:3199-3208

62. Arnold DL 1999 Magnetic resonance spectroscopy: imaging axonal damage in MS J Neuroimmunol 98:2-6

63. Barres BA, Jacobson MD, Schmid R, Sendtner M, Raff MC 1993 Does oligodendrocyte survival depend on axons? Curr Biol 3:489-497

64. Lyons SA, Kettenmann H 1998 Oligodendrocytes and microglia are selectively vulnerable to combined hypoxia and hypoglycemia injury in vitro. J Cereb Blood Flow Metab 18:521-530

65. Weller RO, Williams BN 1975 Cerebral biopsy and assessment of brain damage in hydrocephalus. Arch Dis Child 50:763-768

66. Del Bigio MR, da Silva MC, Drake JM, Tuor UI 1994 Acute and chronic cerebral white matter damage in neonatal hydrocephalus. Can J Neurol Sci 21:299-305

67. Del Bigio MR, Kanfer JN, Zhang YW 1997 Myelination delay in the cerebral white matter of immature rats with kaolin-induced hydrocephalus is reversible. J Neuropathol Exp Neurol 56:1053-1066

68. Del Bigio MR, Zhang YW 1998 Cell death, axonal damage, and cell birth in the immature rat brain following induction of hydrocephalus. Exp Neurol 154:157-169

69. Murphy EJ, Roberts E, Horrocks LA 1993 Aluminum silicate toxicity in cell cultures. Neuroscience 55:597-605 